\title{
Correction to: Composing new understandings of sustainability in the Anthropocene
}

\section{Sophia Jeong ${ }^{1} \cdot$ Stacey Britton ${ }^{2} \cdot$ Kimberly Haverkos $^{3} \cdot$ Mel Kutner $^{1} \cdot$ Teresa Shume $^{4}$. Deborah Tippins ${ }^{1}$}

Published online: 28 January 2021

(c) Springer Nature B.V. 2021

\section{Correction to: Cult Stud of Sci Educ (2018) 13:299-315 https://doi.org/10.1007/s11422-017-9829-x}

In the original publication the author name Sophia Jeong was incorrectly published. This has been corrected with this Correction.

Publisher's Note Springer Nature remains neutral with regard to jurisdictional claims in published maps and institutional affiliations.

The original article can be found online at https://doi.org/10.1007/s11422-017-9829-x.

Sophia Jeong

sj33678@uga.edu

Stacey Britton

sbritton@westga.edu

Kimberly Haverkos

haverkk@thomasmore.edu

Mel Kutner

mrk19412@uga.edu

Teresa Shume

teresa.shume@ndsu.edu

Deborah Tippins

dtippins@uga.edu

1 University of Georgia, 105 Aderhold Hall, 110 Carlton Street, Athens, GA 30602, USA

2 Department of Early Childhood, University of West Georgia, 1601 Maple St., Carrollton, GA 30118, USA

3 Department of Education, Thomas More College, 333 Thomas More Parkway, Crestview Hills, KY 41017, USA

4 North Dakota State University, P.O. Box 6050, Dept. 2625, Fargo, ND 58108, USA 